\title{
Der besondere Saft
}

\section{Erhard Taverna}

Dr. med., Mitglied der Redaktion

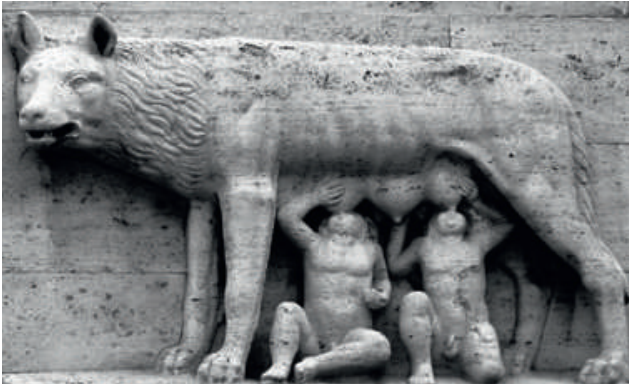

«Professor Muttermilch» titelte die NZZ ihre Nachricht über den weltweit ersten Lehrstuhl in der Medizin für die Muttermilch-Forschung an der Universität Zürich. Die Stiftungsprofessur werde Lücken schliessen und das Renommee weiter verbessern, so der Rektor. Ab 2016 soll das Unternehmen für mindestens 25 Jahre in Betrieb gehen, wofür die Larsson-Rosenquist-Stiftung mit Sitz in Zug einen Betrag von 20 Millionen Franken überweist. Eingebunden in das Projekt sind ab 2016 die Neonatologie und das Kinderspital am USZ. Die Olle Larsson Holding AG betreibt die Medizinfirma Medela AG, bekannt für Bébé-Milchpumpen und medizinische Absauggeräte. Eine zweite Professur für Human Lactology an der University of Australia in Perth soll die Forschung multidisziplinär ergänzen.

Eine Wölfin säugte Romulus und Remus. Zeus wurde mit der Milch einer Ziege aufgezogen. Das wäre durchaus möglich, da bis Ende des 18. Jahrhunderts in vielen französischen Findelhäusern Ziegen die Babys säugten. Tierische Eigenschaften wie Mut und Stärke sollen derart auf den Menschen übergehen. Ohne Affenbrüste kein Tarzan. Das weiss jeder, der dem Dschungelhelden begegnet ist. Doch für Menschen gibt es nichts Besseres, als von der eigenen Mami zu schlucken, zumindest in den ersten sechs Lebensmonaten. Das Wundermittel macht gesund, schlank und schlau, schützt vor Krebs und Allergien und lindert Schmerzen. Fast ebenso sehr profitiert die Spenderin.

Für viele Frauen nach dem Zweiten Weltkrieg war das Nichtstillen auch Ausdruck eines Fortschrittsglaubens. Konserven und Flaschennahrung gehörten zu den Visionen einer besseren Welt. Doch spätestens ab den 1970er Jahren wurde Muttermilch zum Politikum. In der Schweiz begann die Stillförderung der La Leche Liga 1974, die Still- und Lakatationsberaterin wurde zum anerkannten Beruf. 1991 haben WHO und UNICEF die Initiative «Baby-Friendly Hospital» gegründet mit der Empfehlung, über das zweite Lebensjahr hinaus zu stillen. Spitäler, die dem Kodex entsprechen, dürfen eine Anerkennungsplakette vorweisen.

Bei so viel Anerkennung boomt auch das Geschäft. Onlythebreast.com, die führende private Börse für den internationalen Handel, bietet Muttermilch mit Qualität und Liebe. Die Frauen pumpen für Geld, sie nennen sich gemäss dem Magazin Brigitte «Milchmädchen», «mollige Melkmaschine» oder «YummyMommy» und verlangen rund sechs Euro für einen Deziliter. Kontrollen sind nicht vorgeschrieben. Ob die angebliche BioMami Drogen oder Medikamente nimmt, Hepatitis oder HIV überträgt, ist nicht sicher. In Stichproben war jede zehnte Milch in den USA mit Kuhmilch gepanscht und manche mit Bakterien kontaminiert.

Die perfekte Nahrung lockt auch erwachsene Männer an. Bodybuilder und Sportprofis kaufen online Muttermilch für bessere Trainingseffekte. Manche würden am liebsten von einer Amme trinken, was in China zu einer Muttermilch-Mafia geführt hat, die im Prostituiertenmilieu junge Mütter für Säugedienste anbietet.

Die Vorteile des gelblich-weissen Sekrets sind unbestritten. Die Milch ist aber auch ein Indikator für langlebige organische Schadstoffe wie Dioxine, Pestizide, polychlorierte Biphenyle und Furane. Dank Verboten hat die Belastung abgenommen, doch die jüngsten Meldungen über das Herbizid Glyphosat erinnern an den gerne verdrängten Fremdstoff-Cocktail, der auch auf eine Forschungslücke hinweist.

Dem Muttermilch-Professor hilft der Zeitgeist. Wo Eltern ihre Kinder immer später bekommen, geniesst das «Baby-Projekt» erste Priorität. Für die zukünftige IchAG ist jeder Aufwand gerechtfertigt. Eine Studie spricht von Very Important Baby, VIB-Familien. Es darf etwas kosten. Das neue Statussymbol braucht viel Muttermilch und Früherziehung, Frühschwimmen und das Programm «Baby Einstein» vom Disney-Konzern.

Die französische Philosophin Elisabeth Badinter, geboren 1944, Mutter von drei Kindern, äusserte sich immer wieder zu wechselnden Rollenbildern von Mann und Frau. Mit ihren Buch L'Amour en plus (Mutterliebe. Die Geschichte eines Gefühls vom 17. Jahrhundert bis heute) widerspricht sie dem Klischee vom angeborenen Mutterinstinkt. Die Frau als Hauptverantwortliche für das Glück ihres Kindes fixiert sie auf ihre Rolle als Hausfrau und Mutter, was konservativen Familienpolitikern entgegenkommt. Badinter wehrt sich gegen einen traditionellen, biologistischen Dualismus der Geschlechter, der einseitig Identitäten festlegt. Keine Forschung ist unabhängig vom gesellschaftlichen Umfeld. Die Kommentare zur Weltstillwoche im September 2015 werden auch in diesem Licht zu lesen sein. 